\title{
Investigation of Tissue Transglutaminase Antibody Normalization in Response to Gluten-Free Diet in Children with Celiac Disease
}

\author{
Mohsen Pour Ebrahimi ${ }^{1}$ Hosein Alimadadi ${ }^{1}$ Mehri Najafi ${ }^{1} \quad$ Mohammad Vasei $^{2} \quad$ Parisa Rahmani ${ }^{1}$ \\ 1 Pediatric Gastroenterology and Hepatology Research Center, Tehran \\ Address for correspondence Parisa Rahmani, Department of \\ University of Medical Sciences, Tehran, Iran \\ ${ }^{2}$ Cell Therapies Research Center, Digestive Disease Research \\ Institute, Tehran University of Medical Sciences, Shariati Hospital, \\ Pediatrics, Tehran University of Medical Sciences, Tehran, Iran \\ (e-mail: md.p.rahmani@gmail.com).
}

Tehran, Iran

J Child Sci 2021;11:e60-e64.

\begin{abstract}
A very limited amount of data are available regarding the follow-up of celiac disease (CD) treatment in Iran. The aim of this study is to investigate antitissue transglutaminase (atTG) normalization interval and the associated factors in CD patients. This retrospective study included CD patients enrolled in Children's Medical Center, Tehran University of Medical Sciences. The initial atTG titer and histological evaluation (with Marsh grade $\geq 2$ ) were recorded. The atTG titer was assessed in each follow-up until the time of normalization where children were strictly on gluten-free diet. The age

Keywords

- celiac disease

- antitissue transglutaminase

- pediatric

- children

- antibody normalization

- marsh grade at the time of diagnosis, gender, Marsh grade at the time of diagnosis, other comorbidities, and family history of CD patients were recorded to determine the association of these factors with antibody normalization interval. In total, 71 patients were recruited in the study of which 34 (47.89\%) subjects had atTG level below $20 \mathrm{U} / \mathrm{mL}$ at the average interval of $31.36( \pm 2.89)$ months (95\% confidence interval: $25.7-$ 37.02). There was no significant difference between the antibody normalization interval and different age ranges and Marsh grade. Cox regression demonstrated that gender, age ranges, Marsh grade, positive family history of $C D$, and the presence of comorbidities did not significantly predict longer antibody normalization interval.
\end{abstract}

\section{Introduction}

Celiac disease (CD), an immune-mediated systemic disorder, is associated with several gluten-dependent clinical manifestations, CD-related antibodies, HLA-DQ2 or HLA- DQ8 haplotypes, and enteropathy. ${ }^{1,2}$ The immune-mediated reaction to the gluten results in intestinal inflammation, villous atrophy, and malabsorption. The prevalence of $\mathrm{CD}$ among European countries is $1.5 \%$ and in the United states is approximately $1 \%$ in the children below 5 years of age. ${ }^{3,4}$ The symptomatic $\mathrm{CD}$ is presented by gastrointestinal anomalies,

received

October 21, 2020 accepted after revision December 25, 2020
DOI https://doi.org/ 10.1055/s-0041-1724033. ISSN 2474-5871. growth impairment, other autoimmune disorders, osteoporosis, and malignancies. ${ }^{5}$ In 1990, the diagnosis of CD was proposed to be confirmed in the light of histological, serological, and clinical findings, without the need for gluten-free diet (GFD), ${ }^{6}$ and repeated biopsies. The small-bowel mucus villous atrophy and crypt hyperplasia are known histological indications of $\mathrm{CD}$. A study indicated that $22 \%$ of patients were asymptomatic despite the positive histologic evaluations for villous atrophy. ${ }^{7}$ According to American Gastroenterological Association (AGA), serological test for tissue transglutaminase-immunoglobulin A (TG2-IgA), and duodenal biopsy in

\section{(C) 2021. The Author(s)}

This is an open access article published by Thieme under the terms of the Creative Commons Attribution License, permitting unrestricted use, distribution, and reproduction so long as the original work is properly cited. (https://creativecommons.org/licenses/by/4.0/) Georg Thieme Verlag KG, Rüdigerstraße 14, 70469 Stuttgart, Germany 
accordance with Marsh classification are the first two best practices for the diagnosis of $\mathrm{CD}$. However, combination of TG2-IgA with antiendomysial (EMA) IgA antibody provides a very strong diagnostic accuracy. ${ }^{8}$ No simple and reliable test has been reported to be associated with clinical activity and GFD compliance. ${ }^{9,10}$ The guidelines suggest a serial antitissue transglutaminase (atTG) evaluation to investigate the response to the GFD. ${ }^{11,12}$ Previous studies suggest that the undetectable titer of atTG-IgA is associated with mucosal healing during the follow-up. ${ }^{13}$ For evaluating the atTG IgA, enzyme-linked immunosorbent assay has an acceptable sensitivity (90-98\%) and specificity (95-97\%) for CD., ${ }^{5,14,15}$ These antibodies have an important role in diagnosing the newly presented cases with $\mathrm{CD}$; however, their role for the determination of the mucosal recovery is vague. ${ }^{14,16}$ The positive predictive value for the EMA and TTG changes according to the level of the antibodies ${ }^{17}$; where, higher levels have higher positive predictor values. Additionally, higher levels of antibodies are more sensitive and specific for villous atrophy. The aim of this study is to investigate the atTG normalization interval in CD patients and the associated factors as the predictor of the normalization interval.

\section{Patients and Methods}

This retrospective study was performed between March 2018 and September 2018 in Children's Medical Center, Tehran University of Medical Sciences, Tehran, Iran. All known cases of $C D$, diagnosed at Children's Medical center, were evaluated. The exclusion criteria were defined as the presence of IgA deficiency, less than three follow-ups for atTG titer, nonadherence to GFD (verbal assessment), and diagnosis of CD based on serology and not intestinal biopsy.The intestinal biopsies were performed at a maximum interval of 1 month following the abnormal serology. All biopsies were evaluated by the pathologists who were uninformed about the antibody titer, and the specimens were assessed based on the modified Marsh UEGW criteria. ${ }^{18,19}$ Enzyme-linked immunoassay was used to measure the atTG titer by using commercial kit (Orgentec, Germany), where normal antibody titer was defined less than 20 units per milliliter $(\mathrm{U} / \mathrm{mL}){ }^{20}$ The initial atTG titer and histological evaluation (with Marsh grade of at least 2) were recorded. The atTG titer was assessed in each follow-up until the time of normalization. At the time of diagnosis, these patients initiated GFD. Age and Marsh grade at the time of diagnosis, gender, other medical anomalies, and family history of $\mathrm{CD}$ were recorded for each subject to determine the association of these factors with antibody normalization interval. This study was approved by the research ethics board of Tehran University of Medical Sciences.

\section{Statistical Analysis}

The quantitative variables were expressed by mean and standard deviation, and number and percentage were used for the qualitative variable. The median time to at TG normalization was calculated by Kaplan-Meier survival analysis (50\% patients having normalized results). Log- rank test was used to assess the significance of KaplanMeier survival analyses by determining the $p$-value. The association between the predictor variables and the normalization interval was determined by univariate regressions and the Cox regression model that included the independent variables, such as the age of diagnosis, gender, other medical comorbidities, family history of $\mathrm{CD}$, and Marsh grade at time of diagnosis, to determine the association of predictor factors and atTG antibody normalization interval. A $p$-value $<0.05$ was considered statistically significant.

\section{Results}

Of the total 556 patients with the high level of atTG, 137 patients were presented with the Marsh score $\geq 2$ based on the biopsy. Of the 137 patients, 66 subjects had less than three follow-ups for atTG titer or did not adhere to GFD; therefore, 71 patients were eligible to be recruited in the study. In total, $42(59.15 \%)$ of these patients were females, with $25.56 \%$ of them with the age more than 10 years ( - Table 1). The histological study of the patients revealed Marsh 2 lesion in 11 (15.94\%) subjects and Marsh 3 lesion in $58(84.06 \%$ ) (-Table 1 ). In total, $18.3 \%$ of the patients in our study had type 1 diabetes, $4(5.64 \%)$ patients had a positive family history of $\mathrm{CD}, 13$ (18.31\%) had type 1 diabetes mellitus (DM), and 1 (1.41\%) had hepatitis.

Table 1 Characteristics of the evaluated patients

\begin{tabular}{|c|c|}
\hline Variable & Number (\%) \\
\hline \multicolumn{2}{|l|}{ Gender } \\
\hline Female & $42(59.15)$ \\
\hline Male & $29(40.85)$ \\
\hline \multicolumn{2}{|l|}{ Age range (y) } \\
\hline$<4$ & $12(18.75)$ \\
\hline $4-6$ & $12(18.75)$ \\
\hline $6-8$ & $15(23.44)$ \\
\hline $8-10$ & $8(12.5)$ \\
\hline$>10$ & $17(25.56)$ \\
\hline \multicolumn{2}{|l|}{ Family history of $C D$} \\
\hline$C D$ in father & $1(1.41)$ \\
\hline$C D$ in siblings & $3(4.23)$ \\
\hline \multicolumn{2}{|c|}{ Concomitant medical problems } \\
\hline Hepatitis & $1(1.41)$ \\
\hline Type 1 diabetes mellitus & $13(18.31)$ \\
\hline \multicolumn{2}{|l|}{ Marsh lesions } \\
\hline 2 & $11(15.94)$ \\
\hline $3 a$ & $14(20.29)$ \\
\hline $3 b$ & $28(40.58)$ \\
\hline $3 c$ & $16(23.19)$ \\
\hline
\end{tabular}

Abbreviation: $C D$, cognitive disability. 


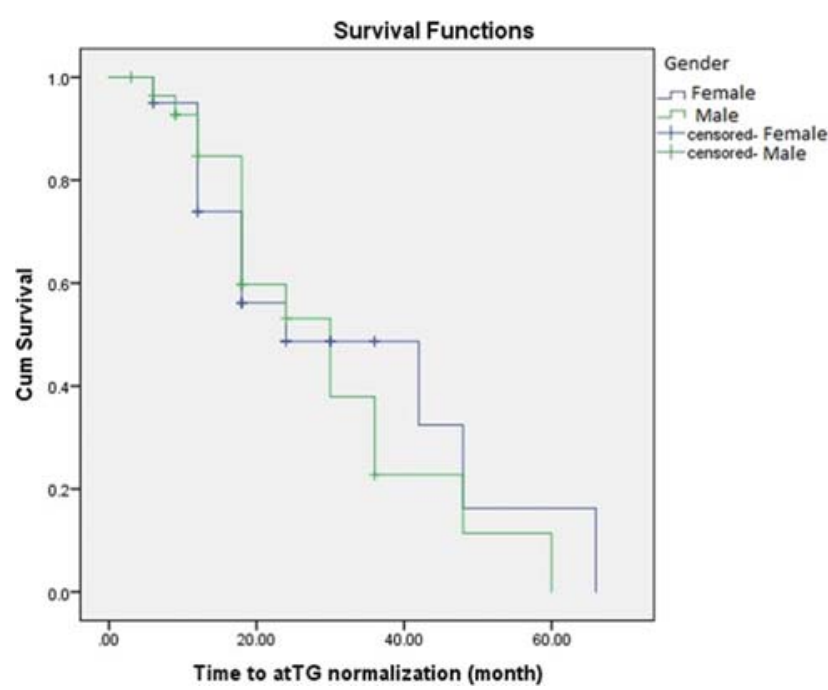

Fig. 1 The Kaplan-Meier survival curve for females and males $(p$-value $=0.7020)$.

\section{Antitissue Transglutaminase Normalization Interval}

In total, 34 (47.89\%) subjects had atTG levels below $20 \mathrm{EU} / \mathrm{mL}$, with 31.36 ( \pm 2.89 ) months average (95\% confidence interval [CI]: 25.7-37.02). The normalization interval for atTG among females was 33.13 ( \pm 4.39 ) months and among males was 29.9 $( \pm 3.84)$ months without any significant difference ( $p$ value $=0.7020 ;$ - Fig. 1 ). There was no significant difference between the antibody normalization interval and different age ranges and Marsh grade, respectively ( $p$-value $=0.5340$ 0.0672; - Table 2; -Figs. 2 and 3). There was no significant correlation between antibody normalization interval and a positive family history of $\mathrm{CD}(p$-value $=0.7726)$. The antibody normalization interval did not differ significantly between the diabetics (25.62 \pm 6.04 months) and nondiabetics (31.29 \pm 2.4 months; $p$-value $=0.1736$ ).

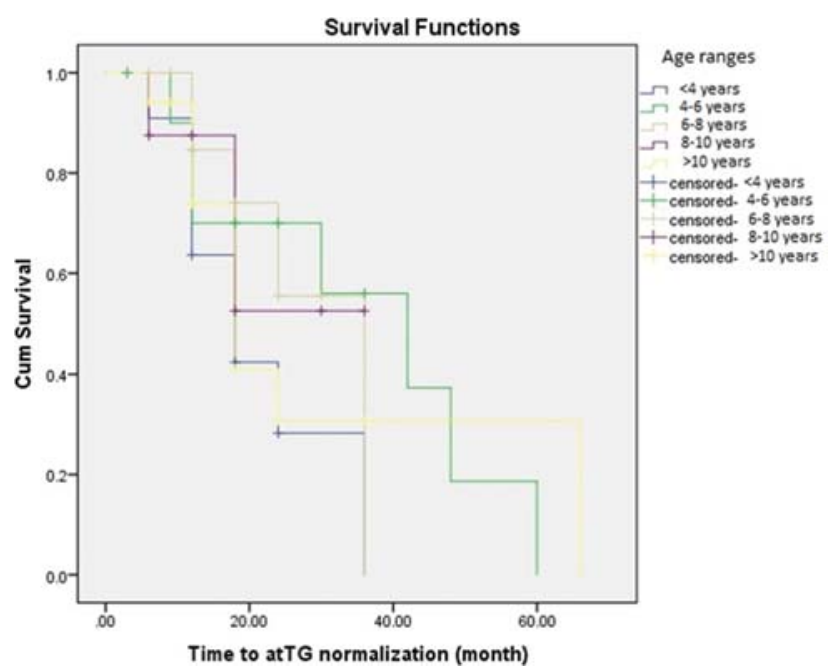

Fig. 2 The Kaplan-Meier survival curve for different age ranges $(p$-value $=0.5340)$.

\section{Independent Predictors of the Antitissue Transglutaminase Normalization Interval}

Cox regression demonstrated that gender $(p$-value $=0.84)$, age ranges $(p$-value $=0.94)$, Marsh grade $(p$-value $=0.24)$, positive family history of $C D(p$-value $=0.75)$, and presence of other comorbidities ( $p$-value $=0.43$ ) did not predict longer antibody normalization interval.

\section{Discussion}

In this study, the atTG levels were reported as greater or lesser than $20 \mathrm{EU} / \mathrm{mL}$ and the exact titer was not determined by the laboratory investigations; therefore, the association between the antibody titers and atTG normalization interval could not be verified. From the patient population, a great

Table 2 Antitissue transglutaminase normalization interval in different age ranges and different Marsh grade

\begin{tabular}{|c|c|c|c|c|c|c|}
\hline & \multirow[t]{2}{*}{ Number of patients with normalized atTG } & \multirow{2}{*}{$\begin{array}{l}\text { Mean } \\
(\mathrm{mo})\end{array}$} & \multirow[t]{2}{*}{ Standard deviation } & \multicolumn{2}{|l|}{$95 \% \mathrm{Cl}$} & \multirow[t]{2}{*}{$p$-Value } \\
\hline & & & & Lower bound & Upper bound & \\
\hline \multicolumn{7}{|c|}{ Age range (y) } \\
\hline$<4$ & 4 & 21.21 & 3.55 & 14.25 & 28.18 & \multirow[t]{5}{*}{0.5340} \\
\hline $4-6$ & 5 & 35.50 & 6.65 & 22.46 & 48.54 & \\
\hline $6-8$ & 10 & 28.18 & 3.46 & 21.41 & 34.96 & \\
\hline $8-10$ & 5 & 25.95 & 4.36 & 17.40 & 34.50 & \\
\hline$>10$ & 7 & 31.49 & 7.08 & 17.61 & 45.37 & \\
\hline \multicolumn{7}{|c|}{ Marsh lesion type } \\
\hline 2 & 10 & 32.00 & 3.65 & 24.84 & 39.16 & \multirow[t]{4}{*}{0.0672} \\
\hline $3 a$ & 7 & 38.14 & 6.08 & 26.21 & 50.06 & \\
\hline $3 \mathrm{~b}$ & 11 & 32.02 & 4.53 & 23.15 & 40.90 & \\
\hline $3 c$ & 5 & 20.43 & 3.03 & 14.48 & 26.37 & \\
\hline
\end{tabular}

Abbreviations: atTG, antitissue transglutaminase; $\mathrm{Cl}$, confidence interval. 


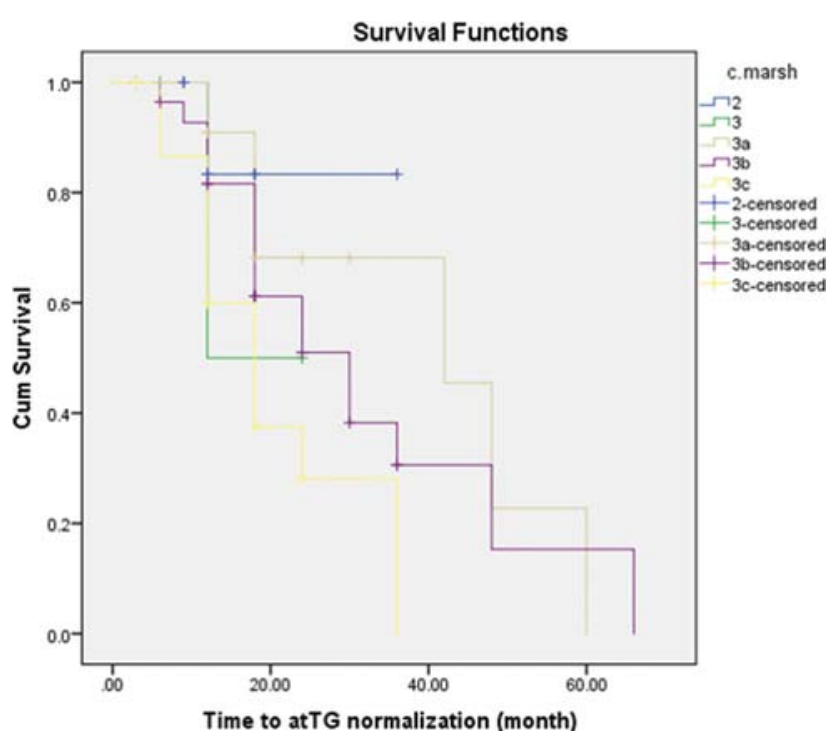

Fig. 3 The Kaplan-Meier survival curve for different Marsh $(p$-value $=0.0672)$.

number of patients did not show up for the follow-up sessions. Based on the evaluations of the pathologists, a remarkable portion of the intestinal specimens was suboptimal to assess. They were small, fragmented, or poorly oriented. Average normalization time was 31.36 months in our study. Gidrewicz et $\mathrm{al}^{21}$ reported that the normalization time among GFD compliant patients was $68.8 \pm 7.3$ months, whereas in a retrospective study by Isaac et al ${ }^{22}$ normalization time was 407 days for all the patients and 364 days for GFD compliant patients. Discrepancies in these findings can be the result of sensitivity/specificity of diagnostic kit, strict adherence of patients to GFD, and knowledge regarding GFD.

Patients with type $1 \mathrm{DM}$ and $\mathrm{CD}$ have a higher atTG titer. ${ }^{22}$ These patients have a more complex dietary program and consequently lower compliance. ${ }^{23,24}$ In 2003, Liu et al indicated that the level of atTG fluctuated over time in DM 1 and $\mathrm{CD}$-susceptible patients. They indicated that the antibody normalization was seen even with a gluten-containing diet and recommended a higher threshold of the antibody titer for diagnosis of $\mathrm{CD} .{ }^{25}$ In our study, the mean atTG normalization interval was less than nondiabetics, although it was not statistically significant (25.62 vs. 31.29 months). Parents' awareness and greater diet control in diabetic patients could be the cause of this finding.

Isaac et al reported the median time for normalization of the atTG to be 407 days for $80.5 \%$ of patients and 364 days for GFD patients. ${ }^{22}$ Hogen Esch et al reported that the cumulative percent of the patients for whom atTG became normal at $6,12,18$, and 24 months was $35,55,64$, and $78 \%$, respectively. ${ }^{26}$ Current guidelines suggest serial atTG measurements and the normalization could be reached within the 12 months following the GFD. ${ }^{11,12}$ The atTG normalization interval in the current study was $31.36( \pm 2.89)$ months, which is higher than the previous studies. This is likely to reflect poorer GFD control in these patients.

The gold standard treatment of CD includes GFD, avoiding ingestion of food items that contain gluten. The goal of the treatment is both improving the symptoms and avoiding complications in the future. Avoiding gluten in the populations with gluten-rich diets is considerably difficult and it can affect the quality of life of the patients. Based on the study of Fabiani and Catassi, strict GFD results in declining of the atTG. ${ }^{27}$ Ciacci et al found that the atTG level can indicate the GFD compliance and is associated with the presence and intensity of the intestinal damage. ${ }^{28}$ The parents' knowledge about the gluten-containing food was considerably limited and they were not aware of the importance of being on GFD, which could be the reason of slower TTG normalization. The GFD compliance routinely was assessed by gastroenterologists by the means of verbal communication. It casts the light on the necessity of being referred to a dietitian to evaluate the GFD compliance tightly; besides giving practical recommendations about the foods containing gluten.

\section{Conclusion}

There was no association between Marsh score, age group, and atTG normalization interval, respectively. None of these factors could predict atTG normalization interval in this study. However, studies comparing the normalization time in GFD compliance group and noncompliance group can give better conclusion.

\section{Note}

All procedures performed in this study involving human participants were in accordance with the ethical standards of the institutional and/or national research committee and with the 1964 Helsinki Declaration and its later amendments or comparable ethical standards. Data sharing not applicable to this article as no datasets were generated or analyzed during the current study.

\section{Authors' Contributions}

M.P.E. and H.A. conceptualized and designed the study, drafted the initial manuscript, and reviewed and revised the manuscript. P.R. designed the data collection instruments, collected data, performed the initial analyses, and reviewed and revised the manuscript. M.N. and M.V. coordinated and supervised data collection, and critically reviewed the manuscript for important intellectual content.

\section{Funding}

None.

Conflict of Interest

None declared.

\section{References}

1 Vriezinga SL, Schweizer JJ, Koning F, Mearin ML. Coeliac disease and gluten-related disorders in childhood. Nat Rev Gastroenterol Hepatol 2015;12(09):527-536

2 Lundin KE, Qiao S-W, Snir O, Sollid LM. Coeliac disease - from genetic and immunological studies to clinical applications. Scand J Gastroenterol 2015;50(06):708-717

3 Celiac U. Professional eXG, newsletters/january-2011-professional-exg. Accessed 2018 at: https://ijcp.in/Admin/CMS/PDF/14.\% 20Pediatrics_IJCP_March_2018.pdf 
4 Hoffenberg EJ, MacKenzie T, Barriga KJ, et al. A prospective study of the incidence of childhood celiac disease. J Pediatr 2003;143 (03):308-314

5 Fasano A. Clinical presentation of celiac disease in the pediatric population. Gastroenterology 2005;128(04, Suppl 1):S68-S73

6 Walker-Smith. Revised criteria for diagnosis of celiac disease. J Arch Dis Child 1990;65:909-911

7 Lähdeaho M-L, Mäki M, Laurila K, Huhtala H, Kaukinen K. Smallbowel mucosal changes and antibody responses after low- and moderate-dose gluten challenge in celiac disease. BMC Gastroenterol 2011;11(01):129

8 Husby S, Murray JA, Katzka DA. AGA clinical practice update on diagnosis and monitoring of celiac disease-changing utility of serology and histologic measures: expert review. Gastroenterology 2019;156(04):885-889

9 Stuckey C, Lowdon J, Howdle P. Joint BAPEN and British Society of Gastroenterology Symposium on 'Coeliac disease: basics and controversies'. Dietitians are better than clinicians in following up coeliac disease. Proc Nutr Soc 2009;68(03):249-251

10 Biagi F, Andrealli A, Bianchi PI, Marchese A, Klersy C, Corazza GR. A gluten-free diet score to evaluate dietary compliance in patients with coeliac disease. Br J Nutr 2009;102(06):882-887

11 Husby S, Koletzko S, Korponay-Szabó IR, et al; ESPGHAN Working Group on Coeliac Disease Diagnosis ESPGHAN Gastroenterology Committee European Society for Pediatric Gastroenterology, Hepatology, and Nutrition. European Society for Pediatric Gastroenterology, Hepatology, and Nutrition guidelines for the diagnosis of coeliac disease. J Pediatr Gastroenterol Nutr 2012;54(01):136-160

12 Rubio-Tapia A, Hill ID, Kelly CP, Calderwood AH, Murray JAAmerican College of Gastroenterology. ACG clinical guidelines: diagnosis and management of celiac disease. Am J Gastroenterol 2013; 108(05):656-676, quiz 677

13 Fang H, King KS, Larson JJ, et al. Undetectable negative tissue transglutaminase IgA antibodies predict mucosal healing in treated coeliac disease patients. Aliment Pharmacol Ther 2017; 46(07):681-687

14 Hopper AD, Hadjivassiliou M, Hurlstone DP, et al. What is the role of serologic testing in celiac disease? A prospective, biopsyconfirmed study with economic analysis. Clin Gastroenterol Hepatol 2008;6(03):314-320

15 Hussain S, Sabir MU, Afzal M, Asghar I. Coeliac disease-clinical presentation and diagnosis by anti tissue transglutaminase antibodies titre in children. J Pak Med Assoc 2014;64(04):437-441

16 Vécsei AK, Graf UB, Vogelsang H. Follow-up of adult celiac patients: which noninvasive test reflects mucosal status most reliably?1 Endoscopy 2009;41(02):123-128
17 Gidrewicz D, Potter K, Trevenen CL, Lyon M, Butzner JD. Evaluation of the ESPGHAN Celiac Guidelines in a North American pediatric population. Am J Gastroenterol 2015;110(05):760-767

18 Marsh MN. Gluten, major histocompatibility complex, and the small intestine. A molecular and immunobiologic approach to the spectrum of gluten sensitivity ('celiac sprue'). Gastroenterology 1992;102(01):330-354

19 United European Gastroenterology. When is a coeliac a coeliac? Report of a working group of the United European Gastroenterology Week in Amsterdam, 2001. Eur J Gastroenterol Hepatol 2001; 13(09):1123-1128

20 Waisbourd-Zinman O, Hojsak I, Rosenbach Y, et al. Spontaneous normalization of anti-tissue transglutaminase antibody levels is common in children with type 1 diabetes mellitus. Dig Dis Sci 2012;57(05):1314-1320

21 Gidrewicz D, Trevenen CL, Lyon M, Butzner JD. Normalization time of celiac serology in children on a gluten-free diet. J Pediatr Gastroenterol Nutr 2017;64(03):362-367

22 Isaac DM, Rajani S, Yaskina M, Huynh HQ, Turner JM. Antitissue transglutaminase normalization postdiagnosis in children with celiac disease. J Pediatr Gastroenterol Nutr 2017;65(02): 195-199

23 Sud S, Marcon M, Assor E, Palmert MR, Daneman D, Mahmud FH. Celiac disease and pediatric type 1 diabetes: diagnostic and treatment dilemmas. Int J Pediatr Endocrinol 2010;2010(01): 161285

24 Hill ID, Dirks MH, Liptak GS, et al; North American Society for Pediatric Gastroenterology, Hepatology and Nutrition. Guideline for the diagnosis and treatment of celiac disease in children: recommendations of the North American Society for Pediatric Gastroenterology, Hepatology and Nutrition. J Pediatr Gastroenterol Nutr 2005;40(01):1-19

25 Liu E, Bao F, Barriga K, et al. Fluctuating transglutaminase autoantibodies are related to histologic features of celiac disease. Clin Gastroenterol Hepatol 2003;1(05):356-362

26 Hogen Esch CE, Wolters VM, Gerritsen SA, et al. Specific celiac disease antibodies in children on a gluten-free diet. Pediatrics 2011;128(03):547-552

27 Fabiani E, Catassi CInternational Working Group. The serum IgA class anti-tissue transglutaminase antibodies in the diagnosis and follow up of coeliac disease. Results of an international multicentre study. International Working Group on Eu-tTG. Eur J Gastroenterol Hepatol 2001;13(06):659-665

28 Ciacci C, Cavallaro R, della Valle N, d'Argenio G. The use of serum tTG-ab assay in patients on gluten-free diet as a measure of dietetic compliance. Gastroenterology 2002;122(02):588 